\title{
Mattoso Câmara: Um Novo Discurso Sobre o Estudo da Linguagem no Brasil
}

(Mattoso Câmara: A New Discourse About Language Study in Brazil)

\author{
Carlos Eduardo Falcão UchôA \\ $(U F F)$ \\ Contar é muito dificultoso. Não pelos anos que já se passaram, \\ mas pela astúcia que têm certas coisas passadas. \\ Guimarães Rosa
}

ABstRACT. The present article shows reverence to Mattoso Câmara's work as a relevant part of the historical process of language studies in Brazil, within the period that goes from the early 1940s to the end of the 1960s, in which the most significative intellectual contribution of the celebrated author was produced. Especially noteworthy are: the search for general principles applicable to any language; the structuralist background in the description of Portuguese; and the anthopological approach to language.

KEY-WORDS: Mattoso Câmara; Structuralism; Linguistics and Anthropology.

RESUMO: O presente artigo reverencia a obra de Mattoso Câmara como parte relevante do processo histórico dos estudos sobre a linguagem no Brasil, no periodo situado entre o limiar da década de 40 e os fins da década de 60, em que se situa a contribuição mais significativa da produção intelectual do homenageado. Destacam-se: a busca de princípios gerais aplicáveis a qualquer língua; o referencial estruturalista na descrição do português; a visão antropológica da linguagem.

PalavRas-CHAVE: Mattoso Câmara; Estruturalismo; Lingüistica e Antropologia.

Que dizer hoje, quando se homenageia Mattoso Câmara, no centenário do seu nascimento, decorridos trinta e quatro anos de seu falecimento? Que dizer hoje, nesta publicação especialmente a ele dedicada, sobre a sua produtiva e abrangente obra, acerca da qual tanto já foi escrito, merecedo- 
ra até mesmo de dissertação e teses ${ }^{1}$ ? Que ficará dela como marca de pioneirismo e de influência no campo do estudo da linguagem no contexto brasileiro no século XX? Para responder tal indagação é fundamental posicionar a obra de Mattoso Câmara no processo histórico dos estudos sobre a linguagem no Brasil, no período situado entre o limiar da década de 40 - seus primeiros artigos, publicados no Correio da Manhã, datam de 1934 e a primeira edição em livro de Princípios é de 1941-e os fins da década de 60 , em que se situa a contribuição mais significativa de sua produção intelectual.

$\mathrm{Na}$ verdade, quando se afirma, e consensualmente, que Mattoso Câmara foi o introdutor da Lingüística moderna no Brasil, o que tal afirmação significa, a rigor, é que, com ele, se inicia uma forma distinta de trabalho com a linguagem entre nós, que se concretiza em um novo discurso, cuja caracterização me proponho aqui.

Este novo discurso sobre a linguagem inaugurado por Mattoso Câmara no Brasil, no início da década de 40, privilegiaria, antes de mais nada, o estudo da linguagem em seu plano universal, vale dizer, um discurso marcado pela preocupação teórica, pelo escopo de fazer lingüística teórica, de trabalhar com uma teoria lingüística cujos princípios gerais fossem aplicáveis a qualquer língua. Com efeito, em 1941, ele edita os seus Princípios de Lingüística Geral (Mattoso Câmara 1941), ainda, pois, no início de uma produção acadêmica que se revelaria notável para a progressão dos estudos lingüísticos em língua portuguesa. Princípios, como alguns críticos já salientaram, não apresenta teoria original, mas revela o trabalho de um lingüista bem informado, atualizado, cuja seleção de temas assegurava uma cobertura satisfatória dos domínios da Lingüística desenvolvidos à época, e com a sempre presente originalidade da reflexão pessoal do autor. As preocupações teóricas não estiveram evidentemente ausentes de estudiosos brasileiros anteriores ou coevos de Mattoso Câmara. Foi ele, contudo, com

São do meu conhecimento: Angela França. Texto e Contexto nos Escritos Lingüísticos de Mattoso Câmara (1938-1954). Dissertação de Mestrado. São Paulo/USP, 1998; Válter Kedhi. A Morfologia e a Sintaxe portuguesas na obra de J. Mattoso Câmara Jr. Tese de livre-docência. São Paulo/USP, 1998; Nilda Santos Cabral. Edição Crítica de Textos Científicos. Proposta de Edição Crítica de Princípios de Lingüústica Geral, de Mattoso Câmara Jr. Tese de doutoramento. São Paulo/USP, 1998; Angela França. Para uma Historiografia de Resolução de Problemas: da 'Arte de Dizer' na Fala Carioca às Descrições da Variante Oral do Português Brasileiro (1937-1960). Tese de doutoramento. São Paulo/USP, 2003. 
Princípios, o primeiro a divulgar, no Brasil, e também em Portugal, um discurso mais abrangente e conseqüente, voltado para a depreensão dos princípios fundamentais que regem o funcionamento da atividade lingüística entre os homens, graças, como reconhece Rodrigues (1984: 91), "à ampla compreensão que desde cedo desenvolveu acerca da linguagem e das línguas e à pertinência e à sabedoria com que atuou através de seus livros", e do seu magistério, acrescento eu. Pode-se dizer que a Lingüística Geral, ou Teórica, como prefiro denominá-la, é reconhecida como disciplina entre nós a partir dos Princípios de Mattoso Câmara e passa a integrar o currículo de um curso de Letras em 1948, quando ele se torna professor regente de Lingüística na Faculdade Nacional de Filosofia da Universidade do Brasil, docência que exerceu ininterruptamente até pouco antes de falecer.

O discurso de Princípios contrastava nitidamente com o discurso sobre o estudo da linguagem então dominante no Brasil, discurso centrado na língua portuguesa, identificado como discurso filológico, com ênfase em dois grandes centros ou campos de interesse: os estudos diacrônicos e os estudos que tinham como objetivo documentar e analisar a língua literária no extenso período que vai do século XVI aos inícios do século XX, período que, embora acolhendo inevitavelmente variações lingüísticas mais ou menos amplas - causa das famosas divergências entre os gramáticos - era apresentado como representativo de uma mesma tradição lingüística. $\mathrm{O}$ discurso dialetológico se inclui também "claramente como uma das ramificações da Filologia ampla, que se propunha o estudo completo das línguas, responsabilizando-se pelos falares, principalmente regionais" (Coelho 1988: 118).

O discurso de Mattoso Câmara sobre a linguagem distinguia-se também do de seus contemporâneos por divulgar um referencial teórico novo entre nós: o estruturalismo. O lingüista brasileiro se apresentava, por ocasião da 1a. edição de Princípios e no correr dos anos 40 e 50, como representante isolado, no Brasil e em Portugal, do discurso teórico estruturalista, opondo-se deste modo ao discurso dominante dos filólogos, de orientação atomista, quer no estudo da língua, sobretudo a literária, quer no estudo diacrônico do vernáculo. Na edição de 1941 de Princípios, Mattoso esclarece alguns fundamentos básicos da lingüística estrutural: explica as dicotomias de Saussure e dedica um capítulo à Fonologia, com base nas idéias de Sapir e do Círculo Lingüístico de Praga, Trubetzkoy à frente. Raras são as referências do lingüista brasileiro ao discurso dos mais consagrados autores 
da tradição filológica de língua portuguesa. Recorde-se ainda que, já em 38, Mattoso Câmara traduziu a obra do lingüista, também estruturalista, e antropólogo norte-americano Edward Sapir, só publicada em 1954, A linguagem: Introdução ao Estudo da Fala, (cf. Sapir 1954[1938]), que se propunha dar uma visão de conjunto da linguagem e suas relações com outros interesses humanos básicos. Com a tradução de Sapir, Mattoso produz também um discurso metalingüístico bem dissonante do que se valiam os estudiosos da época para falar de etimologias ou para analisar fatos da língua literária e de falares regionais.

É graças ao referencial teórico estruturalista que nosso primeiro lingüista pôde também inaugurar um novo enfoque com um novo discurso em relação ao português, no nível histórico da linguagem, por conseguinte. Assim, uma obra como Para o Estudo da Fonêmica Portuguesa (cf. Mattoso Câmara 1953) significa, de fato, uma pesquisa pioneira em nossa língua, destoante dos estudos que então se faziam sobre seus sons. Com a publicação de importantes trabalhos, mormente nos anos 60 , no campo dos estudos gramaticais do português, ele contribuiria decisivamente para uma mudança fundamental na direção dos estudos sobre o português e, em conseqüência, no seu ensino na Universidade. Com efeito, com a obra descritiva de Mattoso Câmara, o estudo que, com Saussure, se passaria a chamar sincrônico, com base no conceito de sistema (estrutura, para o mestre genebrino), se constituiria em uma nova forma bem distinta de trabalhar com a língua, desvinculada do interesse filológico de estudar a língua literária identificada como padrão. Já tive ocasião, em outro trabalho (cf. Uchôa 1997), de assumir a posição de que o estudo científico da língua portuguesa, no Brasil, só é reconhecido como objeto da Lingüística, e não mais da Filologia, quando, justamente, sobretudo no correr dos anos 60, a língua portuguesa começa a ser descrita sob o novo enfoque estrutural. Não se tratava, a meu ver, de mera mudança do nome da ciência para a identificação da competência quanto ao estudo científico da língua. Tal substituição sinalizava uma nova orientação iniciada justamente pela Lingüística moderna, e, pois, um novo discurso metalingüístico na abordagem sincrônica da língua. Sílvio Elia, na apresentação de História e Estrutura da Lingua Portuguesa (cf. Mattoso Câmara 1975), testemunha a propósito que, antes dos estudos descritivos de Mattoso Câmara, a parte do leão, nas universidades, cabia à diacronia, como objeto central do discurso filológico. 
Por fim, mas não menos importante, Mattoso Câmara, ao considerar a Lingüística uma ciência antropológica, iria, já nos anos 40, desenvolver uma outra característica importante do seu novo discurso sobre a linguagem no Brasil, centrado na idéia de que as línguas são produtos da cultura. Desde cedo, o mestre brasileiro tinha entrado em contato com a obra de um Humboldt, de um Boas, de um Sapir, em suma, de lingüistas com visão antropológica da linguagem. Sabe-se que ele dedica parte expressiva da trajetória de suas pesquisas e de sua produção acadêmica ao estudo das línguas indígenas brasileiras.

O estudo filológico não descurava evidentemente do fator cultural, "extremamente útil para a realização dos estudos de 'história humana', respondendo pelo delineamento dos traços socioculturais de um grupo de falantes de uma língua" (Coelho 1998:114-115). Mas a Filologia nunca foi considerada ciência antropológica, tendo centrado mais seus estudos na língua literária. Diria que é típica do discurso filológico a expressão língua de cultura para se referir apenas à língua que goza de uma longa tradição escrita e literária.

Ficando fora do ensino universitário até o final dos anos 40, depois da experiência de 38, na efêmera Universidade do Distrito Federal, Mattoso Câmara entra em contato, nesta época, com os antropólogos do Museu Nacional do Rio de Janeiro, com os quais colaborou continuada e dedicadamente, tendo atuação destacada na orientação deles quanto à importância da Lingüística para os seus estudos. Graças à determinação da então diretora do Museu, Dra. Heloísa Alberto Torres, é que ele conseguiu uma bolsa de estudos nos Estados Unidos (1943-44).

Pode-se assim, até certo ponto, compreender - o conhecimento das condições históricas mostra-se sempre importante para o entendimento do embate ou confronto de idéias - que, ao ingressar, quase à chegada dos anos 50, na Faculdade Nacional de Filosofia, verdadeiro templo do discurso filológico, Mattoso Câmara se tenha tornado figura isolada e até mesmo marginalizada; mesmo tendo obtido, já em 1949, o grau de doutor em Letras Clássicas, e logo a seguir, em 1952, o título de livre-docente em Língua Portuguesa, Mattoso Câmara não alcançou, até o fim de sua carreira, ao término dos anos 60 , a condição de professor catedrático, uma vez que a Lingüística se manteve como uma disciplina, não logrando conquistar o status de Cadeira. Seu discurso, como se viu, voltado, de início, mais 
para a teoria lingüística e para uma visão antropológica da linguagem e, depois, para o estudo do português, com um referencial teórico novo entre nós, divergia cabalmente do discurso dominante, à época, em um curso de Letras.

Mattoso Câmara, na verdade, era um scholar que gozava de uma situação especial: mantinha contato estreito com o mundo filológico (membro fundador da Academia Brasileira de Filologia) e, ao mesmo tempo, era "o lingüista de plantão das reuniões dos antropólogos”, nas décadas de 40 e 50.

Para explicitar mais a sua visão antropológica da linguagem, valhome de textos do lingüista brasileiro, extraídos de alguns seus trabalhos. Tais textos não se prestariam evidentemente a documentar o discurso filológico:

Cada homem que fala, rege-se por um sistema de sons, de fonemas e de significação e ordenação de formas, que ele hauriu da sociedade em que vive e que nesta se transmite através de gerações como uma tradição de cultura, à maneira dos processos de plantar ou de fabricar vasos. Vista desse ângulo, a língua surge-nos com o caráter do que se chama em etnologia uma arte coletiva. O seu estudo pode colocar-se ao lado do das grandes instituições sociais, e a lingüística assume a aparência de uma seção da etnologia. (Mattoso Câmara 1944: 29-30).

Se estão certas até aqui as nossas considerações, é óbvio que entre a lingüística e a etnologia há um estreito ar de família; uma e outra estudam artes coletivas. (Mattoso Câmara 1944:30)

Trata-se, pois, [a linguagem] essencialmente de um fato cultural; é um produto do homem na base de suas faculdades humanas, tanto como outros produtos materiais ou mentais. Assim, Tylor colocava a linguagem entre os objetos culturais, para o fim de pesquisa antropológica, ao lado da indústria, da organização social, da religião, etc. (Mattoso Câmara 1972: 267)

[...] a língua é, em última análise, uma parte da cultura e pertence teoricamente à antropologia. O seu estudo esclarece muitos problemas antropológicos, e o mesmo se pode dizer da antropologia para problemas lingüísticos. (Mattoso Câmara 1972: 272)

Há, entretanto, certas condições que tornam a língua como uma coisa à parte em face dos fatos não-vocais de cultura. (Mattoso Câmara 1972: 268)

Assim, a LÍNGUA, em face do resto da cultura, é - o resultado dessa cultura, ou sua súmula, é o meio para ela operar, é a condição para ela subsistir. E mais ainda: só existe funcionalmente para tanto: englobar a cultura, comunicá-la e transmiti-la. 
Isto opõe naturalmente a língua ao resto da cultura, ou cultura stricto sensu, e cria uma ciência independente para estudá-la - a lingüística em face da antropologia, que estuda todas as outras manifestações culturais. (Mattoso Câmara 1972: 269)

É importante registrar, ainda documentando o discurso antropológico de Mattoso Câmara, que a palavra cultura, palavra certamente base deste discurso, já aparece no texto da 2a. edição revista e aumentada de Princípios (1954) e mais expressivamente como verbete a partir da 2a. edição do Dicionário de Filologia e Gramática (cf. Mattoso Câmara 1964: 106):

Conjunto das criações do homem que constituem um universo humano, ou SUPERORGÂNICO, acima do universo físico, ou inorgânico, e do universo biológico, ou orgânico. As línguas são produtos da cultura para permitir a comunicação social.

Creio que o mais importante num estudo sobre o processo histórico dos discursos sobre a linguagem no Brasil é apreciá-los em sua própria época, caracterizar-lhes os objetivos, depreendendo a contribuição alcançada por cada um. A compreensão de que os vários discursos científicos sobre a linguagem constituem direções ou perspectivas, de igual modo válidas, que se sucedem e se complementam no estudo de um objeto tão complexo, é postura básica que se espera de um cientista e, pois, de um pesquisador da história das idéias lingüísticas no Brasil. Foi a postura de Mattoso Câmara em relação aos seus antecessores e contemporâneos. Iniciador de um novo discurso sobre o estudo da linguagem em nosso país, o lingüista brasileiro sempre soube reconhecer, em várias passagens de sua produção acadêmica, o mérito da contribuição de um grupo de filólogos brasileiros dos mais capacitados que investigaram, com rigor e aprofundamento, o português com outros interesses dos dele, produzindo obras de inestimável valor.

Se o discurso da Lingüística moderna se iniciou e se firmou entre nós com o discurso estruturalista de Mattoso Câmara, é de se esperar que os nossos estudiosos da linguagem tenham sempre a consciência de que os vários discursos que lhe sucederam - o do gerativismo, o da sociolingüística, o da pragmática, o da lingüística do texto... - se complementam na verdade, e não se excluem, direcionados que são a objetos ou interesses distintos que o amplo campo da linguagem comporta. Só assim alcançarão a necessária compreensão da progressão que o estudo científico do fenômeno lingüístico vai suscitando, encarado de diferentes planos e perspectivas, a exigirem sempre novos discursos.

E-mail: ceuchoa@highway.com.br 


\section{REFERÊNCIAS}

Coelho, Olga Ferreira. 1998. Serafim da Silva Neto (1917-1960) e a Filologia Brasileira: um ensaio historiográfico sobre o papel da liderança na articulação de um paradigma em ciência da linguagem. Dissertação de Mestrado. Faculdade de Filosofia, Letras e Ciências Humanas, USP.

Mattoso CÂmara Jr., Joaquim. 1941. Princípios de Lingüística Geral como Fundamento para os Estudos Superiores da Língua Portuguesa. Rio de Janeiro: Briguiet. (Reimpr. em 1942).

1944. Lingüística e etnologia. Revista do Museu Nacional, 2: 27-31. 1953 [1949]. Para o Estudo da Fonêmica Portuguesa. Rio de Janeiro: Organização Simões. (2a. ed., preparada por Raimundo Barbadinho Neto de acordo com instruções deixadas pelo autor. Rio de Janeiro: Padrão, 1977).

1954. Princípios de Lingüística Geral como Introdução aos Estudos Superiores da Língua Portuguesa, 2a. ed. rev. e ampl. Rio de Janeiro: Acadêmica. (3a. ed. 1958, 4a. ed., 1967.)

1964. Dicionário de Filologia e Gramática: Referente à Língua Portuguesa. 2a. ed. Rio de Janeiro: J. Ozon.

1972. Língua e cultura. In: Carlos Eduardo Falcão Uchôa (sel. e introdução.) Dispersos de J. Mattoso Câmara Jr. Rio de Janeiro: Fundação Getúlio Vargas.

1975. História e Estrutura da Língua Portuguesa. Rio de Janeiro: Padrão.

Rodrigues, Aryon Dall'Igna. 1984. A obra científica de Mattoso Câmara Jr. Cadernos de Estudos Lingǘsticos, 6: 83-94.

SAPIR, Edward. 1954[1938]. A linguagem: Introdução ao Estudo da Fala. (Trad. de J. Mattoso Câmara Jr.). Rio de Janeiro: Instituto Nacional do Livro.

UchôA, Carlos Eduardo Falcão. 1972. (sel. e introdução.) Dispersos de J. Mattoso Câmara Jr. Rio de Janeiro: Fundação Getúlio Vargas.

1997. A Filologia e a Lingüística no Brasil: para a história de uma relação do estudo da linguagem no século XX. In: Pereira, Maria Teresa G. (org.). Lingua e Linguagem em Questão. Rio de Janeiro: Ed. UERJ. 